\title{
Why do we like what we like? When information flow matters
}

\author{
Luca F. Ticini ${ }^{1,2 *}$ and Diana Omigie ${ }^{3,4,5,6}$ \\ ${ }^{1}$ Wellcome Laboratory of Neurobiology, University College London, London, UK \\ 2 The Italian Society for Neuroaesthetics 'Semir Zeki', Trieste, Italy \\ ${ }^{3}$ Laboratoire de Neurosciences Fonctionnelles et Pathologies (EA 4559), Université Lille-Nord de France, Lille, France \\ ${ }^{4}$ Hôpital de la Pitié-Salpêtrière, Paris, France \\ ${ }^{5}$ Centre de Neuro-imagerie de Recherche, Paris, France \\ ${ }^{6}$ Centre de Recherche de I'Institut du Cerveau et de la Moëlle Épinière, UPMC-UMR 7225 CNRS - UMRS 975 INSERM, Paris, France \\ ${ }^{*}$ Correspondence: luca.ticini@gmail.com
}

Edited by:

Daniel S. Margulies, Max Planck Institute for Human Cognitive and Brain Sciences, Germany

Keywords: aesthetics, emotion, music reward value, sensory cortex, connectivity

\section{A commentary on}

Interactions between the nucleus accumbens and auditory cortices predict music reward value

by Salimpoor, V. N., van den Bosch, I., Kovacevic, N., McIntosh, A. R., Dagher, A., and Zatorre, R. J. (2013). Science 340, 216-219. doi: 10.1126/science.1231059

In a recent issue of Science, Salimpoor et al. (2013) reported a study in which they explored the neural correlates of aesthetic reward by measuring brain activity while people listened to a novel piece of music. Their results showed that the degree to which a song is found desirable is well predicted both by the level of activity in the nucleus accumbens and the degree of its functional connectivity with other areas, including the orbitofrontal cortex and the auditory cortices. Interestingly, in a previous study, Zeki and Stutters (2012) demonstrated that subjects' preference for kinetic stimuli correlates not just with the activity of the orbitofrontal cortex, but also with activity in a specific part of the visual cortex, namely area V5. Taken together, these two studies are important in highlighting the role of early sensory cortices in subjective preference, even if indirectly shown in the study by Salimpoor et al. (2013) where there was not a direct relationship between auditory activity and desirability. However, in terms of the synergistic relationship between early sensory cortices and reward regions like the nucleus accumbens, two possibilities remain. One is that greater local processing of stimuli with preferred configurations leads to greater connectivity with emotion areas, while another is that greater feedback from emotion areas to early sensory areas takes place during the processing of favored stimuli. In the absence of a definitive answer to this question in the literature, we propose that the latter option is the more plausible. Indeed, there is considerable evidence of feedback influences originating in distant emotion brain structures, such as the amygdala, on early sensory processing (Vuilleumier and Driver, 2007; Scharpf et al., 2010). Nonetheless, there is also support for the alternative view: indeed, low-level statistical regularities of biological significance may influence perceptual judgments and preference ratings (for a review see Graham and Redies, 2010). For instance, in the aesthetic domain, observers dislike images of abstract art that present unnatural statistics (Fernandez and Wilkins, 2008). We suggest that future investigations that consider the dynamics of information flow in response to aesthetic stimuli will provide insights into how their desirability arises. Such efforts will significantly contribute to characterizing the feedback and feedforward mechanisms involved in aesthetic judgments.

\section{REFERENCES}

Fernandez, D., and Wilkins, A. J. (2008). Uncomfortable images in art and nature. Perception 37, 1098-1113. doi: 10.1068/p5814

Graham, D. J., and Redies, C. (2010). Statistical regularities in art: relations with visual coding and perception. Vision Res. 50, 1503-1150. doi: 10.1016/j.visres.2010.05.002

Salimpoor, V. N., van den Bosch, I., Kovacevic, N., McIntosh, A. R., Dagher, A., and Zatorre, R. J. (2013). Interactions between the nucleus accumbens and auditory cortices predict music reward value. Science 340, 216-219. doi: 10.1126/science. 1231059

Scharpf, K. R., Wendt, J., Lotze, M., and Hamm, A. O. (2010). The brain's relevance detection network operates independently of stimulus modality. Behav. Brain Res. 210, 16-23. doi: 10.1016/j.bbr.2010.01.038

Vuilleumier, P., and Driver, J. (2007). Modulation of visual processing by attention and emotion: windows on causal interactions between human brain regions. Phil. Trans. R. Soc. B Biol. Sci. 362, 837-855. doi: 10.1098/rstb.2007.2092

Zeki, S., and Stutters, J. (2012). A brain-derived metric for preferred kinetic stimuli. Open Biol. 2, 120001. doi: 10.1098/rsob.120001

Received: 18 September 2013; accepted: 13 October 2013; published online: 29 October 2013.

Citation: Ticini LF and Omigie D (2013) Why do we like what we like? When information flow matters. Front. Hum. Neurosci. 7:731. doi: 10.3389/fnhum.2013.00731 This article was submitted to the journal Frontiers in Human Neuroscience.

Copyright (c) 2013 Ticini and Omigie. This is an openaccess article distributed under the terms of the Creative Commons Attribution License (CC BY). The use, distribution or reproduction in other forums is permitted, provided the original author(s) or licensor are credited and that the original publication in this journal is cited, in accordance with accepted academic practice. No use, distribution or reproduction is permitted which does not comply with these terms. 